\title{
Genetic and physiological characterization of the Borrelia burgdorferi ORF BB0374-pfs-metK-luxS operon
}

\author{
Correspondence \\ Brian Stevenson \\ brian.stevenson@uky.edu
}

Received 15 November 2006

Revised 19 March 2007

Accepted 20 March 2007

\author{
Sean P. Riley, Tomasz Bykowski, Kelly Babb,† Kate von Lackum $\ddagger$ \\ and Brian Stevenson
} Department of Microbiology, Immunology and Molecular Genetics, University of Kentucky College
of Medicine, MS415 Chandler Medical Center, Lexington, KY 40536-0298, USA

\section{INTRODUCTION}

Lyme disease is an arthropod-borne zoonotic disease affecting humans and many domesticated and wild animals. The causative agent, Borrelia burgdorferi, is readily able to infect both Ixodes spp. ticks and a variety of vertebrate hosts (Steere, 2001). Throughout the processes of infecting these two distinct host types, and transmission between each, $B$. burgdorferi regulates expression of a large number of both metabolic and host-interface proteins. Deciphering the mechanisms by which $B$. burgdorferi controls gene and protein expression patterns is providing insights into both the physiology of this bacterium and its pathogenic abilities.

tPresent address: BioVitesse, West Lafayette, IN 47906, USA.

łPresent address: Department of Oral Biology, University of Florida College of Dentistry, Gainesville, FL 32610, USA.

Abbreviations: Al-2, autoinducer-2; DPD, 4,5-dihydroxy-2,3-pentanedione; SAH, S-adenosylhomocysteine; SAM, S-adenosylmethionine; $\mathrm{SRH}$, S-ribosylhomocysteine; RTase, reverse transcriptase; Q-RT-PCR, quantitative reverse transcription-PCR.

A supplementary figure showing the results of Q-RT-PCR analysis of luxS transcription by wild-type $(w t), r p o N$ and $r p o S$ B. burgdorferi and two supplementary tables of raw data for the Q-RT-PCR are available with the online version of this paper.
Some species of bacteria utilize the metabolic by-product 4,5-dihydroxy-2,3-pentanedione (DPD) in intercellular (and possibly intracellular) signalling. Several different, spontaneously derived forms of DPD have been identified that can function as signals, which are collectively termed 'autoinducer-2' (AI-2) (Chen et al., 2002; Miller et al., 2004). DPD/AI-2 is produced from the toxic end product of transmethylation reactions, $S$-adenosylhomocysteine $(\mathrm{SAH})$, in a two-step reaction catalysed by the enzymes Pfs and LuxS. Some bacteria, such as the syphilis spirochaete Treponema pallidum, possess Pfs but lack LuxS, and therefore detoxify SAH only to the non-toxic S-ribosylhomocysteine (SRH) (Fraser et al., 1998; von Lackum et al., 2006). Other bacteria, B. burgdorferi included, further degrade SRH to DPD and homocysteine via the LuxS enzyme (Babb et al., 2005; Stevenson \& Babb, 2002; Stevenson et al., 2003; Sun et al., 2004; Xavier \& Bassler, 2003). The majority of bacteria salvage homocysteine for regeneration of methionine, for use in additional transmethylation reactions or protein synthesis (Winzer et al., 2002). B. burgdorferi is among the minority of bacteria which lack methionine synthase, and are therefore unable to utilize the homocysteine produced by LuxS (Babb et al., 2005). Several lines of evidence indicate that B. burgdorferi instead uses the LuxS enzyme to 
synthesize DPD/AI-2 as a means to control gene expression. Addition of either in vitro-synthesized DPD or supernatant from an Escherichia coli strain producing $B$. burgdorferi LuxS to cultured B. burgdorferi results in altered expression levels of a number of borrelial proteins (Babb et al., 2005; Stevenson \& Babb, 2002; von Lackum et al., 2007). A B. burgdorferi luxS mutant, which is unable to synthesize DPD, likewise exhibits altered protein expression patterns as compared with its wild-type parent (Babb et al., 2005; Stevenson \& Babb, 2002; von Lackum et al., 2007). luxS mutant B. burgdorferi are still able to infect mice and ticks, indicating that DPD synthesis is not absolutely essential for infection (Blevins et al., 2004; Hübner et al., 2003). Consistent with those results, luxS mutants can produce all of the proteins identified as being affected by DPD, although mutants produce different levels of those proteins than do wild-type B. burgdorferi (Babb et al., 2005; von Lackum et al., 2006, 2007). Taken together, these data suggest that B. burgdorferi uses DPD as a signal to fine tune gene expression levels, as opposed to a simple on/off switch.

Previous genetic and biochemical analyses identified the $p f s$ and luxS genes of B. burgdorferi on the main chromosome, adjacent to two other genes that are also transcribed in the same direction (Fig. 1) (Babb et al., 2005; Stevenson \& Babb, 2002). The genes on either side of this four-gene cluster are transcribed in opposite directions. The gene flanked by $p f s$ and $l u x S$, open reading frame (ORF) BB0376 (ORF numbering system for B. burgdorferi strain B31 as used by Fraser et al., 1997), bears homology to genes of other species that encode MetK [methionine adenosyltransferase/S-adenosylmethionine (SAM) synthase], which catalyses the production of SAM from methionine and ATP (Fraser et al., 1997). SAM serves as a methyl group donor for cellular methylation reactions, with substrates including DNA, tRNA and chemotaxis proteins (Lu, 2000). Due to widespread requirements for methylation reactions, cellular levels of activated methyl donors affect a broad range of metabolic processes. As an example, the met $K$ gene is indispensable for growth of E. coli (Greene et al., 1973; Newman et al., 1998; Wang et al., 2005; Wei \& Newman, 2002). The other uncharacterized gene, ORF BB0374, lacks any complete homologues outside the genus Borrelia (BLASTP and BLASTN searches of GenBank performed 4 November 2006). The encoded protein does, however, contain an amino acid sequence similar to that found in the HD-GYP subfamily of HD family protein domains (Galperin et al., 1999). To date, all characterized HD domain-containing proteins have metal-dependent phosphohydrolase activity, with substrates that include cyclic di-GMP, guanosine tetraphosphate and tRNA (Aravind \& Koonin, 1998; Galperin et al., 2001; Ryan et al., 2006a). For example, HD-GYP domain proteins of Xanthomonas spp. degrade the small signalling molecule cyclic di-GMP and are linked to both intercellular signalling and pathogenicity (Andrade et al., 2006; Ryan et al., 2006a, b, 2007; Slater et al., 2000). A response regulator protein of B. burgdorferi, Rrp1, synthesizes cyclic di-GMP (Ryjenkov et al., 2005), but the phosphohydrolase responsible for degrading cyclic di-GMP has yet to be identified.

Prior to the current study, nothing was known about the transcriptional organization of $p f s, \operatorname{lux} S$ and their neighbouring genes, other than that $p f s$, luxS, and the ORF located between them are encoded on the same mRNA (Hübner et al., 2003). To better understand the genetics of the B. burgdorferi Pfs-LuxS system, we examined promoter location, transcriptional linkage and regulation of all four of the adjacent genes, in addition to biologically characterizing enzymic activity of the ORF BB0376 protein product.

\section{METHODS}

Bacterial strains and culture. Strains used are described in Table 1. B. burgdorferi were cultivated at $34{ }^{\circ} \mathrm{C}$ in modified BarbourStoenner-Kelly medium (BSK-II, Barbour, 1984). For growth related experiments, BSK-II was inoculated with a $1: 500$ dilution of
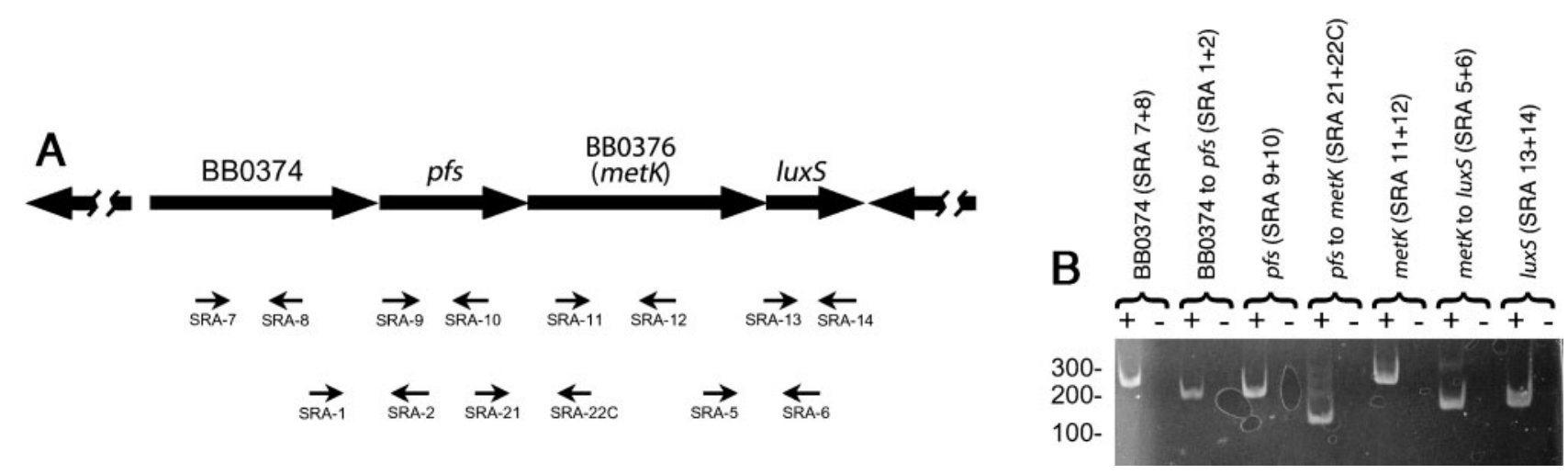

Fig. 1. (A) Diagram of the ORFs described in this work (to scale). Arrows indicating approximate location of oligonucleotides used in (B). (B) Transcriptional linkage analyses. PCR amplification of specific sequences from cDNA produced from total borrelial RNA. + indicates presence of RTase and cDNA production, and - indicates RTase-free RNA controls. 
Table 1. Strains, plasmids and oligonucleotides used in this study

\begin{tabular}{|c|c|c|}
\hline Designation & Relevant characteristics & Source or reference \\
\hline \multicolumn{3}{|l|}{ E. coli strains } \\
\hline MEW402 & MEW1 metK84; leucine-requiring & Newman et al. (1998) \\
\hline SPRM1 & MEW402(pBLS602) & This work \\
\hline \multicolumn{3}{|c|}{ B. burgdorferi strains } \\
\hline B31-MI-16 & Clonal derivative of $\mathrm{B} 31$ & Babb et al. (2005) \\
\hline B31-A3 & Clonal derivative of $\mathrm{B} 31$ & Elias et al. (2002) \\
\hline A3ntrA & B31-A3 ntrA::(PflaB::kan) & Fisher et al. (2005) \\
\hline A3rpos & B31-A3 rpos::(PflaB:: kan $)$ & Elias et al. (2002); Fisher et al. (2005) \\
\hline \multicolumn{3}{|l|}{ Plasmids } \\
\hline pBLS602 & pCR2.1:: B. burgdorferi metK & This work \\
\hline pLuxS4-21 & pCR2.1:: BB0374-luxS & Babb et al. (2005) \\
\hline pSRBA & pCR2.1:: BB0374 promoter & This work \\
\hline pSR1E3 & pET100:: BB0374 & This work \\
\hline pSRE-HD & pET100:: BB0374-HD-GYP domain & This work \\
\hline \multicolumn{3}{|c|}{ Oligonucleotides } \\
\hline SRA1 & $5^{\prime}$-CTAGTGTTCAATCTATAC-3' & \\
\hline SRA2 & 5'-TTCTTCTTTGTTGTCAAG-3' & \\
\hline SRA5 & 5'-CTTGCACTTATGGTCATT-3' & \\
\hline SRA6 & 5'-GAGACATATATGCCAGGG-3' & \\
\hline SRA7 & 5'-TAGGCGCTGCTAGTGCCTATTCTG-3' & \\
\hline SRA8 & 5'-TTGGGTTAGACTCATCTATATCTA-3' & \\
\hline SRA9 & 5'-ACTACAGGAATTGGAAAAGTTAAC-3' & \\
\hline SRA10 & 5'-TTGTGGCAAATTAGGGACTTGTCC-3' & \\
\hline SRA11 & 5'-TAGCTTGCGAGGTCATAATTGCAC-3' & \\
\hline SRA12 & 5'-TTCCCTGATCCCCTGCTCCAAGGG-3' & \\
\hline SRA13 & 5'-AGACATTAGAATCAAAGCTCCCAA-3' & \\
\hline SRA14 & 5'-CCAGTTCTGCATCCCATAGGGCCA-3' & \\
\hline SRA21 & 5'-GCTCAAGTAGCACACATA-3' & \\
\hline SRA22C & 5'-TATTTCTTCTGATTCTTCTTG-3' & \\
\hline SRB2 & 5'-CCTTGTCTAAATATGATGAAT-3' & \\
\hline SRB3 & $5^{\prime}$-GAAATCTTAAAATTGCCAGAA-3' & \\
\hline SRB4 & 5'-TTCTTCTTTGTTGTCAAG-3' & \\
\hline FLA3 & 5'-GGGTCTCAAGCGTCTTGG-3' & \\
\hline FLA4 & 5'-GAACCGGTGCAGCCTGAG-3' & \\
\hline SRE5 & 5'-CACCATGCAAAATTCTGAAAGCATT-3' & \\
\hline SRE6B & 5'-TTATATATAATATCTATTAAAGAATAT-3' & \\
\hline OSPC7 & 5'-CAGGGAAAGATGCGAATACATCTGC-3' & \\
\hline OSPC8 & 5'-TAAGCTAAAGCTAACAATGATCC-3' & \\
\hline METK1 & 5'-TAGGAGGCTAATATGAATAAAATAATAG-3' & \\
\hline METK2 & 5'-ATTTTTTTCATTTTTTTAGCGCTG-3' & \\
\hline SRE-HD 1 & 5'-CACCCACATTATTCATTCGGTAAATACAGC-3' & \\
\hline SRE-HD 2 & 5'-CTATTAGATAGCAGAATAGGCACTAGCGCC-3' & \\
\hline
\end{tabular}

mid-exponential-phase B31-MI-16 $\left(\sim 10^{7}\right.$ bacteria $\left.\mathrm{ml}^{-1}\right)$ and grown at $34{ }^{\circ} \mathrm{C}$ for $2\left(\sim 5 \times 10^{6}\right.$ bacteria $\left.\mathrm{ml}^{-1}\right), 4\left(\sim 1 \times 10^{8}\right.$ bacteria $\left.\mathrm{ml}^{-1}\right), 6$ $\left(\sim 1.5 \times 10^{8}\right.$ bacteria $\left.\mathrm{ml}^{-1}\right)$ or 8 days $\left(\sim 2 \times 10^{8}\right.$ bacteria $\left.\mathrm{ml}^{-1}\right)$. In all other cases, bacteria were harvested when in mid-exponential phase.

metK genetic complementation. E. coli MEW402 contains $\operatorname{lrp}$ and metK84 mutations that make its production of MetK/SAM synthase acutely dependent on the presence of leucine in the culture medium (Newman et al., 1998). A DNA segment of B. burgdorferi B31-MI-16, encompassing ORF BB0376 from the ribosome-binding site to $3^{\prime}$ of the stop codon, was amplified by PCR using oligonucleotide primers METK-1 and METK-2 (Table 1). The resulting amplicon was cloned into pCR2.1 (Invitrogen). One recombinant plasmid, pBLS602, contains the complete ORF BB0376 under the transcriptional control of the plasmid's lac promoter. The insert of pBLS602 was completely sequenced on both strands to ensure that errors had not been introduced during the cloning processes. E. coli MEW402 was transformed with pBLS602 to create E. coli SPRM1. Maintenance of

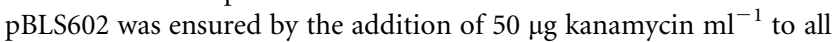
cultures. MEW402 and SPRM1 were each inoculated into M9 medium supplemented with $0.2 \%$ glucose, $2 \mathrm{mg}$ serine $\mathrm{ml}^{-1}$ and $200 \mu \mathrm{g}$ glycine $\mathrm{ml}^{-1}$, with or without $50 \mu \mathrm{g}$ leucine $\mathrm{ml}^{-1}$, and cultured at $37^{\circ} \mathrm{C}$ (Newman et al., 1998). Bacteria were diluted $1: 100$ daily into fresh media for three successive days. After the third passage, IPTG was added to a final concentration of $1 \mathrm{mM}$ to both cultures, inducing transcription of the B. burgdorferi ORF BB0376 in SPRM1, and acting as a control for the parental strain. Wet mounts of bacteria from each culture were examined by darkfield microscopy 
using a Nikon Optiphot, and were photographed at $40 \times$ magnification using a Nikon Coolpix5700 digital camera with $8 \times$ optical zoom.

Production of recombinant ORF BB0374 protein. The complete ORF BB0374 and the internal fragment encoding the HD-GYP domain were PCR amplified from pRW1 (Babb et al., 2005) using primers SRE $5+6 \mathrm{~B}$ or SRE-HD1 +2 respectively (Table 1 ), and cloned into pET100 (Invitrogen) to produce plasmids pSR1E3 and pSREHD. Plasmids were isolated from E. coli and inserts were sequenced. Plasmids were individually transformed into E. coli BL21star(DE3) (Invitrogen), cultured until early exponential phase $\left(\mathrm{OD}_{600} \sim 0.5\right)$, then production of recombinant proteins was induced by addition of IPTG to $1 \mathrm{mM}$. Aliquots were taken hourly for $\mathrm{OD}_{600}$ readings, then bacteria were pelleted by centrifugation for protein analysis. Induction of protein production was assessed by SDS-PAGE followed by either Coomassie brilliant blue staining or transfer and immunoblotting using anti-Xpress antibody (Invitrogen).

RNA isolation and cDNA preparation. Total RNA was extracted from each $B$. burgdorferi culture described above using TRIzol (Life Technologies), resuspended in RNasecure resuspension reagent (Ambion), and treated with DNase I (Ambion) to remove contaminating DNA. Single $1 \mu \mathrm{g}$ aliquots of each DNA-free RNA preparation were reverse transcribed using a First Strand cDNA synthesis kit (Roche) with random hexamers and Avian Myeloblastosis Virus (AMV) reverse transcriptase enzyme (RTase) at $55{ }^{\circ} \mathrm{C}$ for $30 \mathrm{~min}$. The RTase was inactivated for $10 \mathrm{~min}$ at $85{ }^{\circ} \mathrm{C}$ followed by $10 \mathrm{~min}$ at $4{ }^{\circ} \mathrm{C}$.

Primer extension. RNA was isolated from a mid-exponential phase culture of B. burgdorferi strain B31-MI-16 as described above. Primer extensions were performed using the Primer Extension system/AMV Reverse Transcriptase system (Promega) with $\left[\gamma_{-}{ }^{32} \mathrm{P}\right] \mathrm{ATP}$. Briefly, oligonucleotide primers SRB2, SRA2, SRA22C and SRA6 (Table 1) were individually labelled using $\mathrm{T} 4$ polynucleotide kinase, then annealed to the RNA by heating to $58{ }^{\circ} \mathrm{C}$ followed by cooling to room temperature. Primer extension was performed with AMV RTase for $30 \mathrm{~min}$ at $42{ }^{\circ} \mathrm{C}$, and the mixture was immediately heated to $70{ }^{\circ} \mathrm{C}$ with the addition of loading buffer (Promega). DNA markers for size determination were also labelled with $\left[\gamma^{32} \mathrm{P}\right] \mathrm{ATP}$ using T4 polynucleotide kinase. The pSRBA plasmid, which contains the DNA sequence $5^{\prime}$ of ORF BB0374, was constructed by PCR amplification of B. burgdorferi DNA using the primer pair SRB3 +4 and cloned into pCR2.1 (Invitrogen). DNA sequencing was performed on pSRBA (Table 1) using Sequenase version 2.0 (USB) and $\alpha-{ }^{33}$ P-labelled nucleotides. Primer extension and sequencing products, and labelled size markers were simultaneously separated by urea-PAGE, and labelled DNAs were detected by autoradiography.

Linkage analysis. To examine transcriptional linkage, cDNA from mid-exponential-phase cultures of $B$. burgdorferi B31-MI-16 were subjected to PCR with primers SRA1 $+2,5+6,7+8,9+10,11+12$, $13+14$ or $21+22 \mathrm{C}$, to amplify cDNA segments within and spanning the intergenic regions for each of the ORF BB0374, $p f s$, BB0376 $(m e t K)$ and $l u x S$ open reading frames (Table 1 and Fig. 1). Reaction conditions were $94{ }^{\circ} \mathrm{C}$ for $30 \mathrm{~s}, 50{ }^{\circ} \mathrm{C}$ for $30 \mathrm{~s}$, and $68{ }^{\circ} \mathrm{C}$ for $30 \mathrm{~s}$ for 35 cycles. A RTase-free RNA sample was examined using each primer set, to test for DNA contamination. PCR products were resolved in native $6 \%$ polyacrylamide gels stained with ethidium bromide, followed by observation under UV illumination. Each product was also cloned into pCR2.1, and plasmid inserts were sequenced to verify specific amplification.

Quantitative RT-PCR (Q-RT-PCR). cDNA samples were amplified in a LightCycler (Roche Applied Science) and data were analysed as described previously (Miller, 2006). Briefly, cDNA was added to a master mix containing $1 \times$ PCR buffer, enzyme diluent, dNTPs (Idaho Technology), Platinum Taq (Invitrogen), SYBR green (Molecular Probes), nuclease-free water, and oligonucleotide primers $(0.4 \mu \mathrm{M}$ final concentration). Primers used for amplification of flaB, ORF BB0374, $p f$ s, ORF BB0376, and luxS were FLA3 + 4, SRA7 + 8, SRA9 $+10, \quad$ SRA $11+12$ and SRA13 +14 , respectively (Table1). Reaction conditions consisted of a 2 min initial $94{ }^{\circ} \mathrm{C}$ denaturation followed by 50 cycles of $94{ }^{\circ} \mathrm{C}$ for $5 \mathrm{~s}, 55^{\circ} \mathrm{C}(\mathrm{FLA} 3+4$, SRA $11+12$, $13+14)$ or $52{ }^{\circ} \mathrm{C}(\mathrm{SRA} 7+8,9+10)$ for $10 \mathrm{~s}$ and $72{ }^{\circ} \mathrm{C}$ for $30 \mathrm{~s}$. LightCycler software v. 3.5.3 was used for quantification and melting curve analysis (Gilmore et al., 2001). All products were separated by electrophoresis through a $1 \%$ agarose gel and stained with ethidium bromide to verify predicted band size. The cDNA was produced from three independently grown cultures for each time point. Expression values obtained from quadruplicate runs of each cDNA sample for the four genes were calculated relative to the mean quadruplicate value for the B. burgdorferi housekeeping gene flaB from the same cDNA preparation.

To test sigma factor selectivity, DNA-free RNA samples from midexponential-phase cultures of B. burgdorferi A3, A3ntrA, A34rpoS were isolated and cDNAs were synthesized. Transcript levels for luxS, $f l a B$ and $o s p C$ were assessed by Q-RT-PCR as above. The same primers as above were used for $\operatorname{luxS}$ and $f l a B$, while ospC was examined using OSPC7 +8 (Table 1). Reaction conditions for ospC consisted of a $2 \mathrm{~min}$ initial $94{ }^{\circ} \mathrm{C}$ denaturation followed by 50 cycles of $94{ }^{\circ} \mathrm{C}$ for $5 \mathrm{~s}, 52{ }^{\circ} \mathrm{C}$ for $10 \mathrm{~s}$, and $72{ }^{\circ} \mathrm{C}$ for $30 \mathrm{~s}$. All analyses were performed a minimum of three times.

\section{RESULTS}

\section{ORFs BB0374 and BB0376}

Our previous studies demonstrated that B. burgdorferi $p f s$ and luxS encode functional enzymes (Babb et al., 2005; Stevenson \& Babb, 2002). The previously uncharacterized ORF BB0376 is located between $p f s$ and luxS, with all three genes overlapping. ORF BB0376 encodes a potential protein with a $49.4 \%$ identical and $67.8 \%$ similar amino acid sequence to E. coli K-12 MG1655 metK (data not shown). The product of MetK, SAM, serves as a methylgroup donor for biological processes. Upon methyl-group transfer to a substrate, SAM is converted to SAH, the substrate for the Pfs-catalysed reaction. If ORF BB0376 is indeed a $m e t K$ homologue, it would play a role in both borrelial methylation reactions and production of DPD. Since it is inappropriate to assume that genes with similar sequences must necessarily encode enzymically identical proteins, we tested the functionality of the ORF BB0376encoded protein.

Production of MetK is essential for normal growth and cell division of E. coli (Newman et al., 1998; Wang et al., 2005; Wei \& Newman, 2002). E. coli strain MEW402 produces wild-type levels of MetK when grown in medium containing leucine (Fig. 2A). Depletion of leucine leads to inhibition of MetK synthesis, resulting in a septation defect and formation of long filaments (Fig. 2B) (Newman et al., 1998; Wang et al., 2005). Plasmid pBLS602, which contains B. burgdorferi ORF BB0376 under control of the lac promoter, was introduced into MEW402, producing strain SPRM1. Cultures of SPRM1 in media lacking leucine 

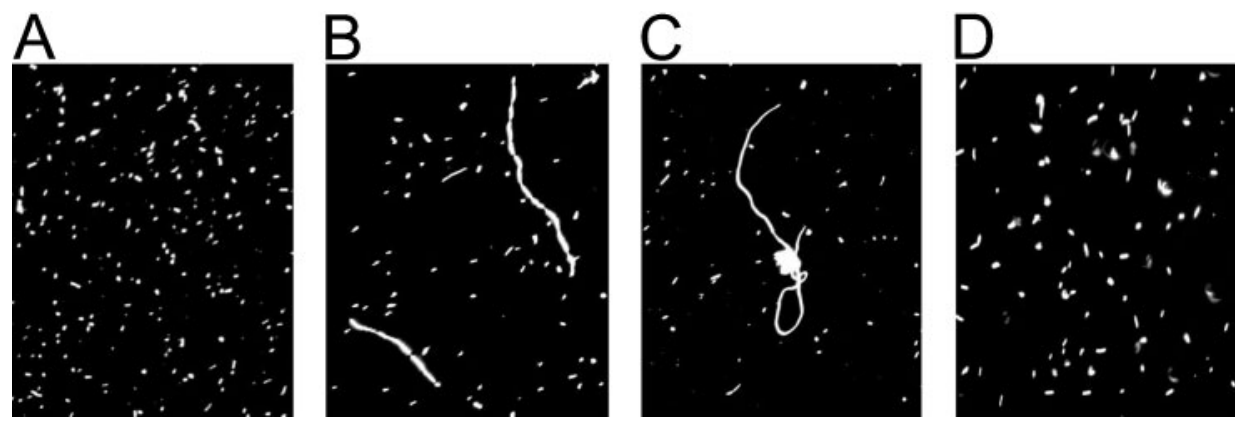

Fig. 2. Genetic complementation of the E. coli MEW402 metK84 mutation by B. burgdorferi ORF BB0376 (metK). All images are shown at the same magnification. (A) MEW402 cultured in minimal medium plus leucine. (B) Septation defect exhibited by MEW402 cultured in medium lacking leucine. (C) Septation defect of E. coli SPRM1 (MEW402 carrying pBLS602) when grown in medium lacking leucine. (D) Restoration of cell division in SPRM1 grown in leucine-deficient medium following IPTG induction of B. burgdorferi ORF BB0376. These results are comparable to those obtained previously when metK84 E. coli was complemented with the wild-type E. coli metK gene (Newman et al., 1998).

formed filaments similar to those of the parent strain (Fig. 2C). Induction of the lac promoter by addition of IPTG restored normal cell division, and the filamentous phenotype was not observed (Fig. 2D). IPTG had no such effect on the parental strain MEW402 (data not shown). This complementation indicated that ORF BB0376 is indeed a metK homologue, and it will be referred to as such through the remainder of this report.

To attempt characterization of the ORF BB0374-encoded protein, constructs were made that directed production of either recombinant full-length protein or the HD-GYP domain only. However, E. coli carrying either of these constructs ceased growth immediately upon induction of recombinant protein synthesis. In contrast, induction of recombinant borrelial Pfs or LuxS production by E. coli using the same T7 polymerase/pET-based expression system had no apparent negative effects upon E. coli growth. Due to the apparent toxicity of the ORF BB0374 gene product to E. coli, we were unable to assess whether or not it is the borrelial cyclic di-GMP phosphohydrolase. We are continuing to pursue alternative approaches to expressing recombinant ORF BB0374 protein, to answer that question.

\section{ORF BB0374, pfs, metK and luxS form an operon}

The four genes in question are each transcribed in the same direction and are flanked by genes that are transcribed in opposite directions. There are very few noncoding nucleotides between the four genes: between ORF BB0374 and $p f s$ there are $23 \mathrm{bp}$, and there are no bases between $p f s$ and $m e t K$ or $m e t K$ and luxS. These observations suggest that all four genes are possibly co-transcribed. Indeed, a previous RT-PCR study indicated that $p f s$ and $m e t K$ are included on the same mRNA, as are metK and luxS (Hübner et al., 2003). We extended that earlier work by demonstrating by RT-PCR that ORF BB0374 and $p f s$ are also transcribed on the same mRNA (Fig. 1). The tight spacing of the four genes would prevent Rho-dependent termination prior to the end of luxS. Examination of the sequence spanning ORF BB0374 through luxS did not reveal any inverted repeats that could serve as Rho-independent terminators. Northern blot analysis using probes derived from ORF BB0374 or luxS revealed only a broad RNA smear (data not shown).

Recognizing the possibility that this four-gene locus could have multiple promoters, we performed primer extension analysis on purified B. burgdorferi RNA. A product was obtained only from extensions originating within ORF BB0374 (data not shown). Control analyses without addition of RNA confirmed that the band observed was due to extension from mRNA. This transcriptional start site was finely mapped using high-resolution gels and simultaneous di-deoxy sequencing of a DNA template using the same primer. Two transcription start sites were detected, 23 and 25 bp $5^{\prime}$ of the ORF BB0374 translation initiation codon (Fig. 3). Potential -10 and -35 sequences are located at appropriate distances $5^{\prime}$ of the transcription start sites, as is also a consensus extended -10 sequence.

\section{Growth rate dependent expression of the operon}

A previous study indicated that cultivated B. burgdorferi secrete maximal levels of DPD during the exponential phase of growth, while that compound is largely undetectable in supernatants of stationary-phase cultures (Babb et al., 2005). Q-RT-PCR analysis of each gene in the ORF BB0374- $p f s-m e t K-l u x S$ operon was performed to determine the connection between gene expression and production of DPD, as well as to examine for evidence of independent regulation. To that end, cultures were inoculated at low densities and harvested after 2 days $\left(\sim 5 \times 10^{6}\right.$ cells ml $^{-1}$, early exponential phase, approximately four doublings), 4 days $\left(\sim 1 \times 10^{8}\right.$ cells $\mathrm{ml}^{-1}$ mid-exponential phase, approximately 8 doublings $), 6$ days $\left(\sim 1.5 \times 10^{8}\right.$ cells $\mathrm{ml}^{-1}$,

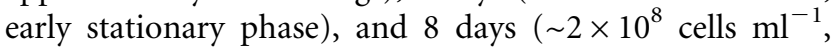
well into stationary phase) (Babb et al., 2005). Total RNA 


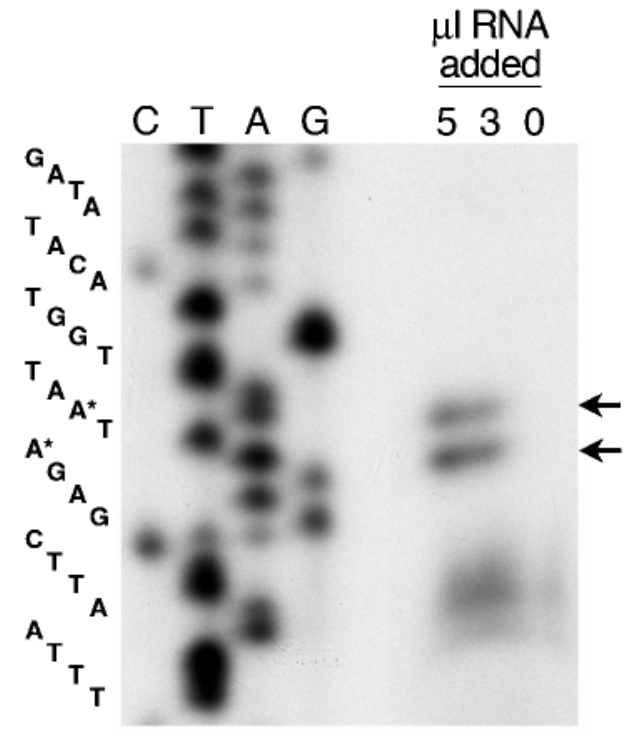

CATAAAAATCTCTTCAAAAAAGCTTAATTCAAA

AATTGAGATATAATAAATACATTATACTAATAGA

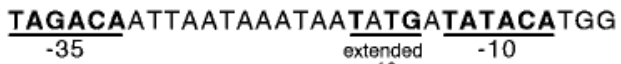
$-35$ 10
.10

TTAATAGAGCTTAATTTCAAGGGAATAAATG

Fig. 3. Fine mapping of the transcriptional start site upstream of ORF BB0374. Primer extension products were electrophoresed with the corresponding DNA sequences. The two specific primer extension products mapped to 23 and $25 \mathrm{bp} 5^{\prime}$ of the start codon for ORF BB0374 (asterisks). Potential -10 , extended -10 , and -35 sites are present $5^{\prime}$ of these transcriptional initiation sites. The sequence CAT in bold type $5^{\prime}$ of ORF BB0374 indicates the initial codon of the divergently transcribed ORF BB0373.

was extracted and transcript levels of each gene were determined (see Supplementary Table S1, available with the online version of this paper). Due to the constitutive expression of $f l a B$, Q-RT-PCR results for ORF BB0374, $p f s$, metK and luxS were standardized relative to the flaB results. Similar relative levels of expression were observed for all four genes of the operon (Fig. 4). Moreover, expression levels of each gene were at least fivefold higher during the early exponential phase of growth than during the later stationary phase.

\section{Sigma factor selectivity of the operon}

B. burgdorferi encodes three RNA polymerase sigma subunits, the housekeeping $\sigma^{70}$ and homologues of $\sigma^{\mathrm{S}}$ and $\sigma^{\mathrm{N}}$. Several studies have implicated the importance of RNA polymerase subunits $\sigma^{\mathrm{S}}$ and $\sigma^{\mathrm{N}}$ in B. burgdorferi transitional events, including transmission from tick to mammal (Caimano et al., 2004; Elias et al., 2000; Yang et al., 2000). Since the ORF BB0374-pfs-metK-luxS operon is induced during tick-to-mammal transmission

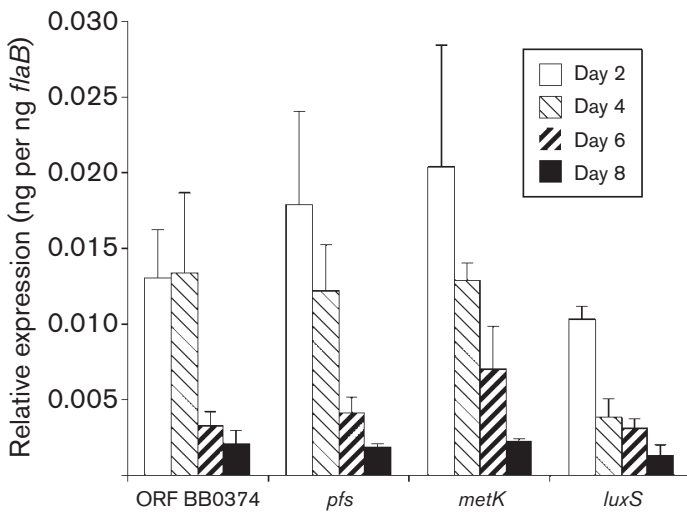

Fig. 4. Growth-phase-dependent expression of ORF BB0374, pfs, metK and luxS. Bacteria were harvested at densities of $6 \times 10^{6}$, $1 \times 10^{8}, 1.5 \times 10^{8}$ and $2 \times 10^{8}$ bacteria $\mathrm{ml}^{-1}$, corresponding to early exponential, mid-exponential, early stationary and late stationary phases, respectively (Babb et al., 2005). Three independently grown cultures were analysed for each time point, and each cDNA was analysed in quadruplicate. Total RNA was extracted and relative mRNA levels analysed by Q-RT-PCR. All results were standardized relative to mRNA levels of the constitutively expressed $f l a B$ gene. Error bars indicate one standard deviation from the mean. Raw data used to generate graphs are presented in Supplementary Table S1.

(Narasimhan et al., 2002), we examined whether either $\sigma^{\mathrm{S}}$ or $\sigma^{\mathrm{N}}$ played a role in regulation of operon transcription. The $\sigma^{\mathrm{S}}$ subunit is induced as cultures approach stationary phase, and $\sigma^{\mathrm{s}}$ levels are dependent on $\sigma^{\mathrm{N}}$ (Caimano et al., 2004; Elias et al., 2000; Yang et al., 2000). B. burgdorferi with specific deletions of either $\operatorname{rpoS}\left(\sigma^{\mathrm{S}}\right)$ or $\operatorname{rpoN}\left(\sigma^{\mathrm{N}}\right)$ produced luxS transcripts at levels comparable to wild-type bacteria (Supplementary Fig. S1, Supplementary Table S2), indicating that neither alternative sigma factor is directly responsible for transcription of this operon. The control gene, $\operatorname{sp} p C$, was not transcribed by either mutant, consistent with previous analyses of that gene (Hübner et al., 2001; Yang et al., 2003). These data indicate that the housekeeping factor $\sigma^{70}$ interacts with the RNA polymerase holoenzyme $5^{\prime}$ of ORF BB0374 to direct transcription of this operon.

\section{DISCUSSION}

The present studies demonstrated that genes encoding the two enzymes responsible for synthesis of DPD from SAH, the enzyme that produces the activated-methyl donor SAM, and a putative phosphohydrolase are contained in a single operon. Evidence was found for only a single transcriptional promoter, located $5^{\prime}$ of the first of the four genes, which uses the housekeeping $\sigma^{70}$ RNA polymerase holoenzyme. All four genes were co-expressed, being produced during the exponential phase of growth, and repressed during the stationary phase. These data are 
consistent with previous observations that $B$. burgdorferi produces maximal levels of DPD/AI-2 during exponential phase, and increased expression of $\operatorname{luxS}$ during the period of rapid growth accompanying transmission from feeding tick vectors to mammalian hosts (Babb et al., 2005; Narasimhan et al., 2002). Thus, high metabolic states are accompanied by increases in three enzymic activities: (1) MetK, which increases cellular levels of the only known borrelial methyl donor, SAM; (2) Pfs, which detoxifies the product of SAM-dependent methylation reactions; and (3) LuxS, which produces DPD and homocysteine. As described above, B. burgdorferi lacks the ability to use homocysteine; the Pfs product, $\mathrm{SAH}$, is not toxic; and the addition of DPD to Lyme disease spirochaetes causes alterations in protein expression patterns. It is likely, therefore, that production of DPD is directly correlated with cellular fitness, and, reciprocally, that DPD may function as a signal of bacterial fitness (Xavier \& Bassler, 2003). Such a signal may function extracellularly, to influence the entire population, intracellularly as an alarmone to modify expression levels of that bacterium's own genes, or as a combination of these two possibilities (Beeston \& Surette, 2002; Camilli \& Bassler, 2006; Redfield, 2002; Xavier \& Bassler, 2003).

Since the product of the MetK-catalysed reaction is converted to the Pfs substrate by cellular methyltransferases, MetK makes a direct contribution to AI-2 synthesis, as well as to regulation of the total cellular methyl pool. In many bacteria, a second major methyl-group donor, methylenetetrahydrofolate (THF), is involved in nucleic and amino acid biosynthesis, but $B$. burgdorferi lacks homologues of most enzymes required for production of THF (Fraser et al., 1997). B. burgdorferi encodes numerous postulated methyltransferases which have potential substrates including tRNA, rRNA, DNA and chemotaxis proteins, with SAM likely to be the only molecule capable of donating activated methyl groups. Therefore, we hypothesize that production of MetK is directly proportional to the rate of total methylation reactions in the cell.

In conclusion, the ORF BB0374-pfs-metK-luxS operon encodes three enzymic activities that directly connect cellular methylation and bacterial growth to production of the signalling molecule DPD. ORF BB0374 encodes a probable phosphohydrolase. The interrelatedness of pathways suggests that regulation of the BB0374-pfs-metK-luxS operon plays a role in coordinating physiological adaptations of $B$. burgdorferi. Elucidating the regulatory mechanisms controlling transcription of this operon and the effects of each gene product will illuminate further our understanding of the biology of $B$. burgdorferi and the mechanisms by which the Lyme disease spirochaete infects its diverse hosts.

\section{ACKNOWLEDGEMENTS}

This work was supported by grant R01-AI49795 from the National Institutes of Health. Sean Riley was supported in part by NIH
Training Grant in Microbial Pathogenesis T32-AI49795 and a University of Kentucky Graduate School Dissertation Year Fellowship. We thank Mark Fisher, Elaine Newman and Patricia Rosa for strains, and Jennifer Miller, Michael Woodman, Anne Cooley, Catherine Brissette, Alex Bobrov, Olga Kirillina and Robert Perry for helpful comments on this work and on the manuscript.

\section{REFERENCES}

Andrade, M. O., Alegria, M. C., Guzzo, C. R., Docena, C., Pareda Rosa, M. C., Ramos, C. H. \& Farah, C. S. (2006). The HD-GYP domain of RpfG mediates a direct linkage between the Rpf quorumsensing pathway and a subset of diguanylate cyclase proteins in the phytopathogen Xanthomonas axonopodis pv citri. Mol Microbiol 62, 537-551.

Aravind, L. \& Koonin, E. V. (1998). The HD domain defines a new superfamily of metal-dependent phosphohydrolases. Trends Biochem Sci 23, 469-472.

Babb, K., von Lackum, K., Wattier, R. L., Riley, S. P. \& Stevenson, B. (2005). Synthesis of autoinducer 2 by the Lyme disease spirochete, Borrelia burgdorferi. J Bacteriol 187, 3079-3087.

Barbour, A. G. (1984). Isolation and cultivation of Lyme disease spirochetes. Yale J Biol Med 57, 521-525.

Beeston, A. L. \& Surette, M. G. (2002). $p f s$-dependent regulation of autoinducer 2 production in Salmonella enterica serovar typhimurium. J Bacteriol 184, 3450-3456.

Blevins, J. S., Revel, A. T., Caimano, M. J., Yang, X. F., Richardson, J. A., Hagman, K. E. \& Norgard, M. V. (2004). The luxS gene is not required for Borrelia burgdorferi tick colonization, transmission to a mammalian host, or induction of disease. Infect Immun 72, 4864-4867.

Caimano, M. J., Eggers, C. H., Hazlett, K. R. \& Radolf, J. D. (2004). $\mathrm{RpoS}$ is not central to the general stress response in Borrelia burgdorferi but does control expression of one or more essential virulence determinants. Infect Immun 72, 6433-6445.

Camilli, A. \& Bassler, B. L. (2006). Bacterial small-molecule signaling pathways. Science 311, 1113-1116.

Chen, X., Schauder, S., Potier, N., Van Dorsselaer, A., Pelczer, I., Bassler, B. L. \& Hughson, F. M. (2002). Structural identification of a bacterial quorum-sensing signal containing boron. Nature 415, 545-549.

Elias, A. F., Bono, J. L., Carroll, J. A., Stewart, P., Tilly, K. \& Rosa, P. (2000). Altered stationary-phase response in a Borrelia burgdorferi rpoS mutant. J Bacteriol 182, 2909-2918.

Elias, A. F., Stewart, P. E., Grimm, D., Caimano, M. J., Eggers, C. H., Tilly, K., Bono, J. L., Akins, D. R., Radolf, J. D. \& other authors (2002). Clonal polymorphism of Borrelia burgdorferi strain B31 MI: implications for mutagenesis in an infectious strain background. Infect Immun 70, 2139-2150.

Fisher, M. A., Grimm, D., Henion, A. K., Elias, A. F., Stewart, P. E., Rosa, P. A. \& Gherardini, F. C. (2005). Borrelia burgdorferi $\sigma^{54}$ is required for mammalian infection and vector transmission but not for tick colonization. Proc Natl Acad Sci U S A 102, 5162-5167.

Fraser, C. M., Casjens, S., Huang, W. M., Sutton, G. G., Clayton, R., Lathigra, R., White, O., Ketchum, K. A., Dodson, R. \& other authors (1997). Genomic sequence of a Lyme disease spirochaete, Borrelia burgdorferi. Nature 390, 580-586.

Fraser, C. M., Norris, S. J., Weinstock, G. M., White, O., Sutton, G. G., Dodson, R., Gwinn, M., Hickey, E. K., Clayton, R. \& other authors (1998). Complete genome sequence of Treponema pallidum, the syphilis spirochete. Science 281, 375-388. 
Galperin, M. Y., Natale, D. A., Aravind, L. \& Koonin, E. V. (1999). A specialized version of the HD hydrolase domain implicated in signal transduction. J Mol Microbiol Biotechnol 1, 303-305.

Galperin, M. Y., Nikolskaya, A. N. \& Koonin, E. V. (2001). Novel domains of the prokaryotic two-component signal transduction systems. FEMS Microbiol Lett 203, 11-21.

Gilmore, R. D., Jr, Mbow, M. L. \& Stevenson, B. (2001). Analysis of Borrelia burgdorferi gene expression during life cycle phases of the tick vector Ixodes scapularis. Microbes Infect 3, 799-808.

Greene, R. C., Hunter, J. S. V. \& Coch, E. H. (1973). Properties of metK mutants of Escherichia coli. J Bacteriol 115, 57-67.

Hübner, A., Yang, X., Nolen, D. M., Popova, T. G., Cabello, P. C. \& Norgard, M. V. (2001). Expression of Borrelia burgdorferi OspC and DbpA is controlled by a RpoN-RpoS regulatory pathway. Proc Natl Acad Sci U S A 98, 12724-12729.

Hübner, A., Revel, A. T., Nolen, D. M., Hagman, K. E. \& Norgard, M. V. (2003). Expression of a $\operatorname{luxS}$ gene is not required for Borrelia burgdorferi infection of mice via needle inoculation. Infect Immun 71, 2892-2896.

Lu, S. C. (2000). S-Adenosylmethionine. Int J Biochem Cell Biol 32, 391-395.

Miller, J. C. (2006). Example of real-time quantitative reverse transcription-PCR (Q-RT-PCR) analysis of bacterial gene expression during mammalian infection: Borrelia burgdorferi in mouse tissues. In Current Protocols in Microbiology, pp. 1D.3.1-1D.3.28. Edited by T. K. R. Cioco, J. M. Quarles, B. Stevenson \& R. K. Tyler. New York: Wiley.

Miller, S. T., Xavier, K. B., Campagna, S. R., Taga, M. E., Semmelhack, M. F., Bassler, B. L. \& Hughson, F. M. (2004). Salmonella typhimurium recognizes a chemically distinct form of the bacterial quorum-sensing signal AI-2. Mol Cell 15, 677-687.

Narasimhan, S., Santiago, F., Koski, R. A., Brei, B., Anderson, J. F., Fish, D. \& Fikrig, E. (2002). Examination of the Borrelia burgdorferi transcriptome in Ixodes scapularis during feeding. J Bacteriol 184, 3122-3125.

Newman, E. B., Budman, L. I., Chan, E. C., Greene, R. C., Lin, R. T., Woldringh, C. L. \& D'Ari, R. (1998). Lack of $S$-adenosylmethionine results in a cell division defect in Escherichia coli. J Bacteriol 180, 3614-3619.

Redfield, R. J. (2002). Is quorum sensing a side effect of diffusion sensing? Trends Microbiol 10, 365-370.

Ryan, R. P., Fouhy, Y., Lucey, J. F., Crossman, L. C., Spiro, S., He, Y. W., Zhang, L. H., Heeb, S., Camara, M. \& other authors (2006a). Cell-cell signaling in Xanthomonas campestris involves an HD-GYP domain protein that functions in cyclic di-GMP turnover. Proc Natl Acad Sci U S A 103, 6712-6717.

Ryan, R. P., Fouhy, Y., Lucey, J. F. \& Dow, J. M. (2006b). Cyclic diGMP signaling in bacteria: recent advances and new puzzles. $J$ Bacteriol 188, 8327-8334.

Ryan, R. P., Fouhy, Y., Lucey, J. F., Jiang, B., He, Y. W., Feng, J., Tang, J. \& Dow, J. M. (2007). Cyclic di-GMP signalling in the virulence and environmental adaptation of Xanthomonas campestris. Mol Microbiol 63, 429-442.
Ryjenkov, D. A., Tarutina, M., Moskvin, O. V. \& Gomelsky, M. (2005). Cyclic diguanylate is a ubiquitous signaling molecule in bacteria: insights into biochemistry of the GGDEF protein domain. J Bacteriol 187, 1792-1798.

Slater, H., Alvarez-Morales, A., Barber, C. E., Daniels, M. J. \& Dow, J. M. (2000). A two-component system involving an HD-GYP domain protein links cell-cell signalling to pathogenicity gene expression in Xanthomonas campestris. Mol Microbiol 38, 986-1003.

Steere, A. C. (2001). Lyme disease. N Engl J Med 345, 115-125.

Stevenson, B. \& Babb, K. (2002). LuxS-mediated quorum sensing in Borrelia burgdorferi, the Lyme disease spirochete. Infect Immun 70, 4099-4105.

Stevenson, B., von Lackum, K., Wattier, R. L., McAlister, J. D., Miller, J. C. \& Babb, K. (2003). Quorum sensing by the Lyme disease spirochete. Microbes Infect 5, 991-997.

Sun, J., Daniel, R., Wagner-Dobler, I. \& Zeng, A. P. (2004). Is autoinducer-2 a universal signal for interspecies communication: a comparative genomic and phylogenetic analysis of the synthesis and signal transduction pathways. BMC Evol Biol 4, 36.

von Lackum, K., Babb, K., Riley, S. P., Wattier, R. L., Bykowski, T. \& Stevenson, B. (2006). Functionality of Borrelia burgdorferi LuxS: the Lyme disease spirochete produces and responds to the pheromone autoinducer-2 and lacks a complete activated-methyl cycle. Int J Med Microbiol 296 (Suppl. 40), 92-102.

von Lackum, K., Ollison, K. M., Bykowski, T., Nowalk, A. J., Hughes, J. L., Carroll, J. A., Zückert, W. R. \& Stevenson, B. (2007). Regulated synthesis of the Borrelia burgdorferi inner-membrane lipoprotein IpLA7 (P22, P22-A) during the Lyme disease spirochete's mammaltick infectious cycle. Microbiology 153, 1361-1371.

Wang, S., Arends, S. J., Weiss, D. S. \& Newman, E. B. (2005). A deficiency in $S$-adenosylmethionine synthetase interrupts assembly of the septal ring in Escherichia coli K-12. Mol Microbiol 58, 791-799.

Wei, Y. \& Newman, E. B. (2002). Studies on the role of the metK gene product of Escherichia coli K12. Mol Microbiol 43, 1651-1656.

Winzer, K., Hardie, K. R., Burgess, N., Doherty, N., Kirke, D., Holden, M. T., Linforth, R., Cornell, K. A., Taylor, A. J. \& other authors (2002). LuxS: its role in central metabolism and the in vitro synthesis of 4hydroxy-5-methyl-3(2H)-furanone. Microbiology 148, 909-922.

Xavier, K. B. \& Bassler, B. L. (2003). LuxS quorum sensing: more than just a numbers game. Curr Opin Microbiol 6, 191-197.

Yang, X., Goldberg, M. S., Popova, T. G., Schoeler, G. B., Wikel, S. K., Hagman, K. E. \& Norgard, M. V. (2000). Interdependence of environmental factors influencing reciprocal patterns of gene expression in virulent Borrelia burgdorferi. Mol Microbiol 37, 1470-1479.

Yang, X. F., Alani, S. M. \& Norgard, M. V. (2003). The response regulator Rrp2 is essential for the expression of major membrane lipoproteins in Borrelia burgdorferi. Proc Natl Acad Sci U S A 100, 11001-11006.

Edited by: R. J. Lamont 